Article

\title{
Inhibition of Butyrylcholinesterase and Human Monoamine Oxidase-B by the Coumarin Glycyrol and Liquiritigenin Isolated from Glycyrrhiza uralensis
}

\author{
Geum Seok Jeong ${ }^{1}$, Myung-Gyun Kang ${ }^{2}$, Joon Yeop Lee ${ }^{3}$, Sang Ryong Lee ${ }^{1}$, Daeui Park ${ }^{2} \mathbb{D}$, \\ MyoungLae $\mathrm{Cho}^{3}$ and Hoon $\mathrm{Kim}^{1, * \mathbb{D}}$ \\ 1 Department of Pharmacy, and Research Institute of Life Pharmaceutical Sciences, \\ Sunchon National University, Suncheon 57922, Korea; fever41@naver.com (G.S.J.); \\ wholsr@naver.com (S.R.L.) \\ 2 Department of Predictive Toxicology, Korea Institute of Toxicology, Daejeon 34114, Korea; \\ myung-gyun.kang@kitox.re.kr (M.-G.K.); daeui.park@kitox.re.kr (D.P.) \\ 3 National Institute for Korean Medicine Development, Gyeongsan 38540, Korea; \\ choo19090@nikom.or.kr (J.Y.L.); meanglae@nikom.or.kr (M.C.) \\ * Correspondence: hoon@sunchon.ac.kr; Tel.: +82-61-750-3751
}

Academic Editor: Maria João Matos

Received: 11 August 2020; Accepted: 25 August 2020; Published: 26 August 2020

\begin{abstract}
Eight compounds were isolated from the roots of Glycyrrhiza uralensis and tested for cholinesterase (ChE) and monoamine oxidase (MAO) inhibitory activities. The coumarin glycyrol (GC) effectively inhibited butyrylcholinesterase $(\mathrm{BChE})$ and acetylcholinesterase (AChE) with $\mathrm{IC}_{50}$ values of 7.22 and $14.77 \mu \mathrm{M}$, respectively, and also moderately inhibited MAO-B $(29.48 \mu \mathrm{M})$. Six of the other seven compounds only weakly inhibited $\mathrm{AChE}$ and $\mathrm{BChE}$, whereas liquiritin apioside moderately inhibited $\mathrm{AChE}\left(\mathrm{IC}_{50}=36.68 \mu \mathrm{M}\right)$. Liquiritigenin $(\mathrm{LG})$ potently inhibited $\mathrm{MAO}-\mathrm{B}\left(\mathrm{IC}_{50}=0.098 \mu \mathrm{M}\right)$ and MAO-A $\left(\mathrm{IC}_{50}=0.27 \mu \mathrm{M}\right)$, and liquiritin, a glycoside of $\mathrm{LG}$, weakly inhibited MAO-B $(>40 \mu \mathrm{M})$. GC was a reversible, noncompetitive inhibitor of BChE with a $\mathrm{K}_{\mathrm{i}}$ value of $4.47 \mu \mathrm{M}$, and LG was a reversible competitive inhibitor of MAO-B with a $\mathrm{K}_{\mathrm{i}}$ value of $0.024 \mu \mathrm{M}$. Docking simulations showed that the binding affinity of GC for BChE $(-7.8 \mathrm{kcal} / \mathrm{mol})$ was greater than its affinity for AChE $(-7.1 \mathrm{kcal} / \mathrm{mol})$, and suggested that GC interacted with BChE at Thr284 and Val288 by hydrogen bonds (distances: 2.42 and $1.92 \AA$, respectively) beyond the ligand binding site of $\mathrm{BChE}$, but that GC did not form hydrogen bond with AChE. The binding affinity of LG for MAO-B $(-8.8 \mathrm{kcal} / \mathrm{mol})$ was greater than its affinity for MAO-A $(-7.9 \mathrm{kcal} / \mathrm{mol})$. These findings suggest GC and LG should be considered promising compounds for the treatment of Alzheimer's disease with multi-targeting activities.
\end{abstract}

Keywords: Glycyrrhiza uralensis; glycyrol; liquiritigenin; cholinesterases; human monoamine oxidases; kinetics; docking simulation

\section{Introduction}

Acetylcholinesterase (AChE, EC 3.1.1.7) catalyzes the breakdown of acetylcholine (ACh), a neurotransmitter found in synapses of the cerebral cortex [1]. AChE inhibitors reduce AChE activity and maintain or increase ACh levels, which are typically deficient in Alzheimer's disease (AD), and thus, enhance cholinergic transmission in brain [2,3]. AD is a chronic, devastating manifestation of neuronal dysfunction and is characterized by progressive mental failure, disordered cognitive functions, and speech impairment. Various cholinesterase inhibitors (e.g., tacrine, donepezil, galantamine, and rivastigmine), immunotherapies, antisense oligonucleotides, phyto-pharmaceuticals, and nutraceuticals are being used to treat $\mathrm{AD}[4]$. 
Butyrylcholinesterase (BChE) breaks down butyrylcholine ( $\mathrm{BCh}$ ), and $\mathrm{BChE}$ levels are significantly elevated in the $\mathrm{AD}$ brain $[5,6]$. Interestingly, $\mathrm{AChE}$ and $\mathrm{BChE}$, which are both related to $\mathrm{AD}$ and act independently, are viewed as diagnostic markers and as potential targets for drug development [7].

On the other hand, monoamine oxidases (MAO, EC 1.4.3.4) catalyze the oxidative deamination of monoamine neurotransmitters and are present as two MAO isoforms, that is, MAO-A and MAO-B, in the outer mitochondrial membranes of all tissues [8]. MAO-A is primarily targeted to treat depression and anxiety, whereas MAO-B is targeted to treat AD and Parkinson's disease (PD) [9]. In addition, MAOs are critically related to amyloid plaque formation in $\mathrm{AD}$, and MAO-B is co-expressed at high levels in the AD brain with $\gamma$-secretase [10].

Due to the complex etiology of $\mathrm{AD}$, multi-targeting therapeutic agents have been devised to inhibit MAOs and AChE, and thus, elevate monoamine and choline ester levels [11]. Recently, multi-targeting agents such as homoisoflavonoid derivatives [12], donepezil-butylated hydroxytoluene hybrids [13], coumarin-dithiocarbamate hybrids [14], alcohol-bearing dual inhibitors [15], and chalcone oxime ethers [16] have been reported to target MAO-B and AChE. Dual function inhibitors of AChE and $\mathrm{BChE}$ have been studied using in silico approaches, such as pharmacophore-based virtual screening and molecular docking [17]. In addition, compounds targeting for MAO-A, MAO-B, AChE, and BChE like TV 3326 [18] and 1,2,3,4-tetrahydrochromeno[3,2-c]pyridin-10-one derivatives [19] have also been described.

Glycyrol (GC), a coumarin derivative, has been reported to have anticancer [20-22], anti-fungal [23], anti-bacterial [24], anti-viral [25,26], anti-inflammatory [27-29], and immunosuppressive activities [30]. However, the ChE inhibitory activity of GC has not been reported to date. Liquiritigenin (LG), a flavonoid, is also known to have many biological activities including MAO inhibitory activity [31,32]. However, these MAO studies were conducted using fractions of rat liver mitochondrial MAO and rat brain MAO-A and MAO-B, respectively.

In the present study, eight compounds were isolated from Glycyrrhiza uralensis (also known as Chinese licorice) and investigated for their inhibitory activities against AChE, BChE, and human MAO-A and MAO-B. The two most potent compounds (GC and LG) were subjected to kinetic analysis and their affinities for the enzymes were investigated using molecular docking simulations.

\section{Results}

\subsection{Isolation and Identification of Compounds}

Eight natural products were isolated from Glycyrrhiza uralensis and identified by comparing NMR data (Supplementary Information) with literature values: GC (1) [33], isoliquiritin (2) [33], LG (3) [33], glycyrrhetinic acid (4) [34], liquiritin (5) [33], liquiritin apioside (6) [35], isoliquiritin apioside (7) [36], and glycyrrhizin (8) [37]. The structures of the eight compounds are detailed in Figure 1.

\subsection{Analysis of Inhibitory Activities}

The AChE, BChE, MAO-A, and MAO-B inhibitory activities of the eight compounds were investigated at a concentration of $10 \mu \mathrm{M}$. Most of the eight inhibited AChE, BChE, MAO-A, and MAO-B by less than $50 \%$. However, GC and LG potently inhibited AChE and BChE, and MAO-A and MAO-B, respectively (Table 1). GC inhibited $\mathrm{BChE}$ and $\mathrm{AChE}$ with $\mathrm{IC}_{50}$ values of 7.22 and $14.77 \mu \mathrm{M}$, respectively, with a selectivity index (SI) of 2.0 for BChE with respect to AChE, and also moderately inhibited MAO-B $(29.48 \mu \mathrm{M})$. Other compounds showed weak inhibitory activities against AChE or BChE, except liquiritin apioside, which moderately inhibited $\mathrm{AChE}\left(\mathrm{IC}_{50}=36.68 \mu \mathrm{M}\right)$. LG potently inhibited MAO-B $\left(\mathrm{IC}_{50}=0.098 \mu \mathrm{M}\right)$ and MAO-A $\left(\mathrm{IC}_{50}=0.27 \mu \mathrm{M}\right)$. The SI value of LG for MAO-B with respect to MAO-A was 2.8 (Table 1). Liquiritin, a LG glycoside, weakly inhibited MAO-A and MAO-B (>40 $\mu \mathrm{M})$. Thus, GC and LG were found to be effective inhibitors of $\mathrm{BChE}$ and MAO-B, respectively. 


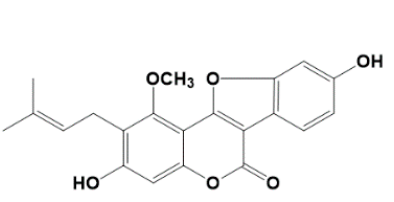

Glycyrol (1)

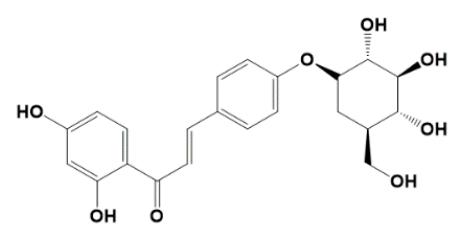

Isoliquiritin (2)

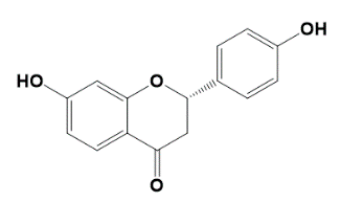

Liquiritigenin (3)

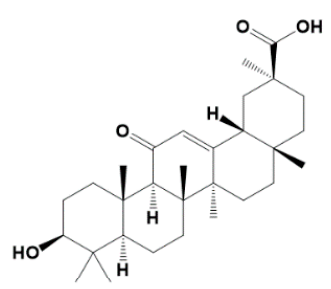

Glycyrrhetinic acid (4)

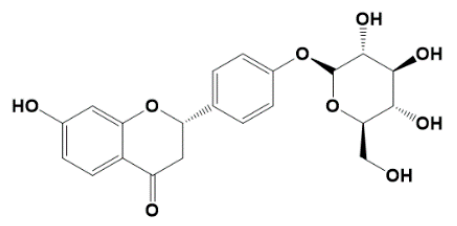

Liquiritin (5)<smiles>O=C1CC(c2ccc(OC3O[C@H](CO)[C@@H](O)[C@H](O)[C@H]3OC3OCC(O)(CO)[C@H]3O)cc2)Oc2cc(O)ccc21</smiles>

Liquiritin apioside (6)

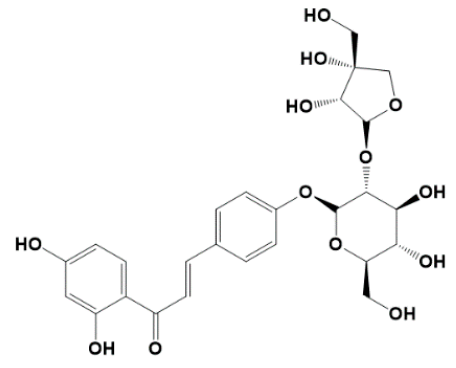

Isoliquiritin apioside (7)

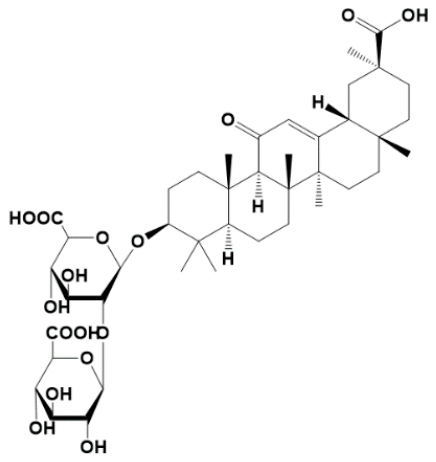

Glycyrrhizin (8)

Figure 1. Chemical structures of eight compounds isolated from the roots of Glycyrrhiza uralensis.

\subsection{Analysis of the Reversibilities of BChE and MAO-B Inhibitions}

Reversibilities of BChE inhibition by GC and of MAO-B inhibition by LG were investigated by dialysis and dilution methods. Residual $\mathrm{BChE}$ activity after GC inhibition recovered partially from $34.6 \%$ (undialyzed activity; $A_{U}$ ) to $58.4 \%$ (dialyzed activity; $A_{D}$ ) by dialysis, whereas inhibition by tacrine (a known reversible inhibitor) significantly recovered from $10.3 \%$ to $74.1 \%$ (Figure $2 \mathrm{~A}$ ). We also confirmed reversibility using the dilution method by measuring and comparing residual $\mathrm{BChE}$ activities of a sample preincubated with GC at a concentration of $50 \times \mathrm{IC}_{50}$ and then diluted to a concentration of $1 \times \mathrm{IC}_{50}$ with a control sample treated at a GC concentration of $1 \times \mathrm{IC}_{50}$. We found that residual activities were similar before and after dilution $(51.1 \%$ and $40.1 \%$, respectively), and that the activity of the sample at a concentration of $50 \times \mathrm{IC}_{50}$ was $10.3 \%$ (Figure $2 \mathrm{~A}$ ). These results suggested that GC is a reversible inhibitor of $\mathrm{BChE}$, because if it acted as an irreversible inhibitor, activity would have been reduced by dilution. On the other hand, the relative residual activity of MAO-B after LG inhibition recovered from $38.4 \%\left(\mathrm{~A}_{\mathrm{U}}\right)$ to $87.2 \%\left(\mathrm{~A}_{\mathrm{D}}\right)$ by dialysis, which was similar to activity recovery observed for the reversible MAO-B inhibitor lazabemide (from $36.1 \%$ to $88.0 \%$ ). On the other hand, values for the irreversible inhibitor pargyline were $17.0 \%$ and $8.4 \%$, respectively (Figure $2 \mathrm{~B}$ ). These results showed that GC and LG reversibly inhibited BChE and MAO-B, respectively.

\subsection{Analysis of Inhibitory Patterns}

Modes of BChE inhibition by GC and of MAO-B inhibition by LG were investigated by analyzing Lineweaver-Burk plots. Plots of BChE inhibition by GC were linear and intersected the $x$-axis (Figure 3A). Secondary plots of the slopes of Lineweaver-Burk plots against inhibitor concentration showed the $\mathrm{K}_{\mathrm{i}}$ value of $\mathrm{GC}$ for BChE inhibition was $4.47 \pm 0.29 \mu \mathrm{M}$ (Figure 3B). 
Table 1. Inhibitions of AChE, BChE, MAO-A, and MAO-B by compounds isolated from the roots of Glycyrrhiza uralensis.

\begin{tabular}{|c|c|c|c|c|c|c|c|c|}
\hline \multirow{2}{*}{ Compounds } & \multicolumn{4}{|c|}{ Residual Activity at $10 \mu \mathrm{M}(\%)$} & \multicolumn{4}{|c|}{$\mathrm{IC}_{50}(\mu \mathrm{M})$} \\
\hline & MAO-A & MAO-B & AChE & BChE & MAO-A & MAO-B & AChE & BChE \\
\hline GC & $70.5 \pm 1.61$ & $74.2 \pm 3.46$ & $46.1 \pm 4.40$ & $44.6 \pm 5.36$ & $>40$ & $29.48 \pm 0.67$ & $14.77 \pm 0.19$ & $7.22 \pm 0.37$ \\
\hline Isoliquiritin & $81.8 \pm 1.61$ & $75.4 \pm 2.27$ & $69.9 \pm 2.20$ & $91.9 \pm 7.16$ & $>40$ & $>40$ & $>40$ & $>40$ \\
\hline LG & $0.46 \pm 1.60$ & $0.00 \pm 3.34$ & $95.3 \pm 3.59$ & $82.5 \pm 0.26$ & $0.27 \pm 0.041$ & $0.098 \pm 0.00079$ & $>40$ & $>40$ \\
\hline Glycyrrhetinic acid & $96.3 \pm 2.64$ & $84.0 \pm 2.16$ & $97.3 \pm 1.61$ & $95.0 \pm 4.12$ & $>40$ & $>40$ & - & - \\
\hline Liquiritin & $93.5 \pm 0.00$ & $90.2 \pm 0.56$ & $93.5 \pm 5.12$ & $95.5 \pm 4.67$ & $>40$ & $>40$ & $>40$ & $>40$ \\
\hline Liquiritin apioside & $86.9 \pm 2.41$ & $94.8 \pm 0.57$ & $63.5 \pm 2.56$ & $97.6 \pm 0.93$ & $>40$ & $>40$ & $36.68 \pm 1.42$ & $>40$ \\
\hline Isoliquiritin apioside & $86.6 \pm 3.27$ & $80.3 \pm 5.57$ & $93.5 \pm 3.07$ & $95.6 \pm 0.88$ & $>40$ & $>40$ & - & - \\
\hline Glycyrrhizin & $95.8 \pm 3.30$ & $93.1 \pm 4.32$ & $97.7 \pm 2.14$ & $82.3 \pm 7.95$ & $>40$ & $>40$ & - & - \\
\hline Toloxatone & & & & & $1.08 \pm 0.025$ & - & - & - \\
\hline Lazabemide & & & & & - & $0.063 \pm 0.015$ & - & - \\
\hline Clorgyline & & & & & $0.007 \pm 0.00070$ & - & - & - \\
\hline Pargyline & & & & & - & $0.028 \pm 0.0043$ & - & - \\
\hline Tacrine & & & & & & - & $0.27 \pm 0.019$ & $0.014 \pm 0.0043$ \\
\hline
\end{tabular}

-, not determined. Values above are the means \pm SEs of triplicate experiments, and $\mathrm{IC}_{50}$ values were graphically determined at three different inhibitor concentrations around its concentration showing $50 \%$ of residual activity. 
(A)

\section{Dialysis method}

Undialyzed

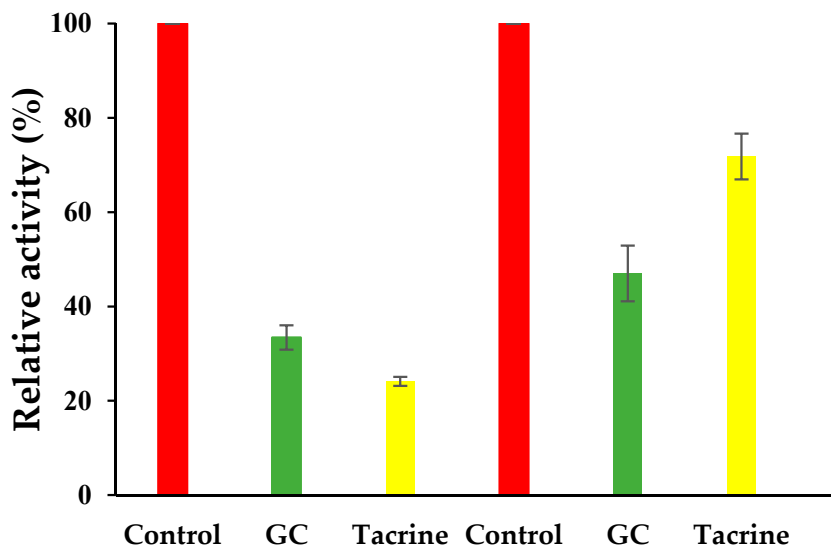

Dilution method

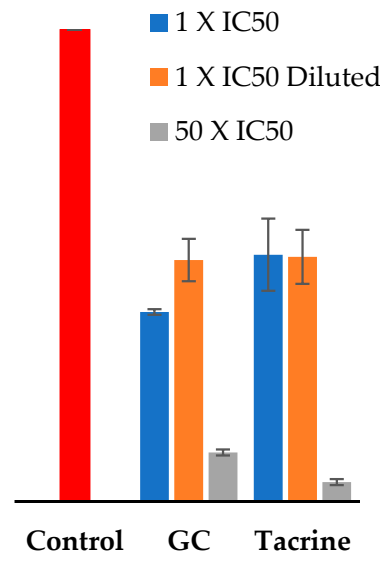

(B)

\section{Dialysis method}

Undialyzed

Dialyzed

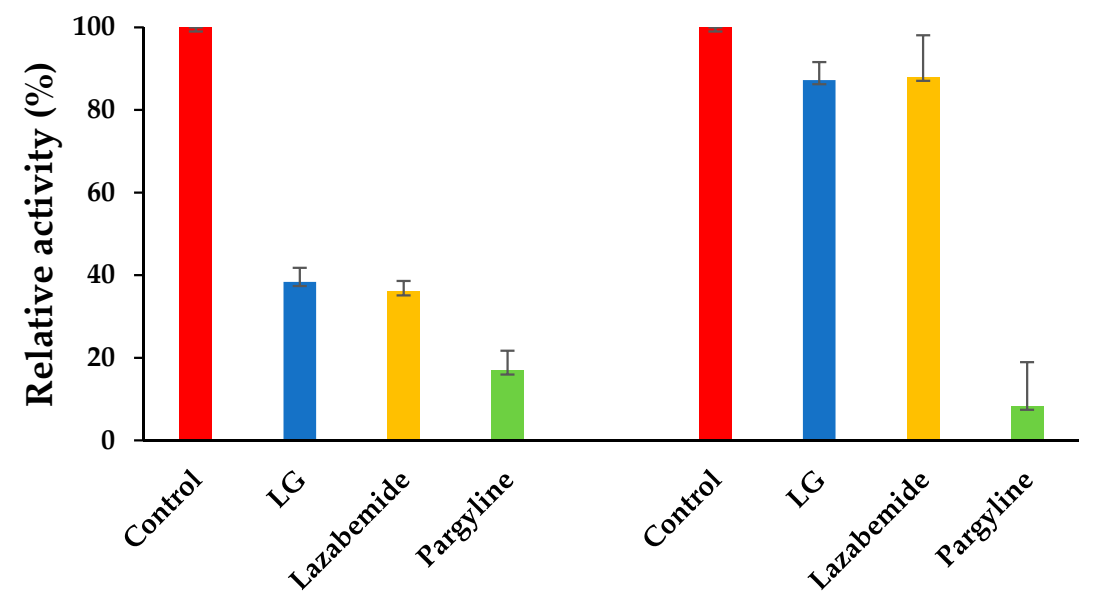

Figure 2. Recoveries of $\mathrm{BChE}$ inhibition by GC (A) and MAO-B inhibition by $\mathrm{LG}(\mathbf{B})$. The concentrations of the inhibitors used were: GC, $14.0 \mu \mathrm{M}$; LG, $0.2 \mu \mathrm{M}$; tacrine, $0.03 \mu \mathrm{M}$; lazabemide, $0.12 \mu \mathrm{M}$; and pargyline, $0.06 \mu \mathrm{M}$. In the dilution experiments, we measured residual activities of $\mathrm{BChE}$ at an inhibitor concentration of $1 \times \mathrm{IC}_{50}$, at a concentration of $50 \times \mathrm{IC}_{50}$ and then diluted to a concentration of $1 \times \mathrm{IC}_{50}$ after preincubation, at an inhibitor concentration of $50 \times \mathrm{IC}_{50}$. Results are the averages of duplicate or triplicate (GC dialysis) experiments. Tacrine was used as a reversible reference $\mathrm{BChE}$ inhibitor. Lazabemide and pargyline were used as reversible and irreversible reference MAO-B inhibitors, respectively. 
(A)

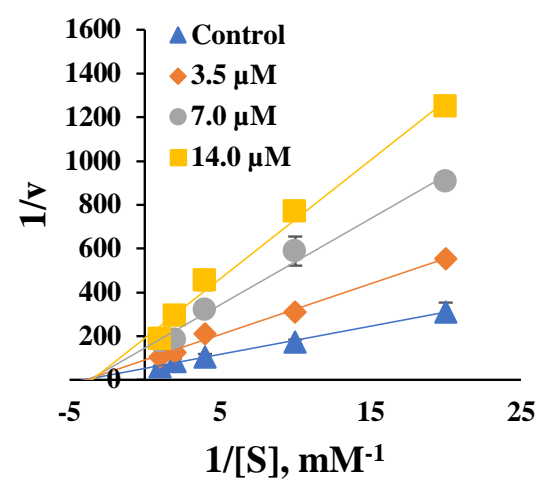

(C)

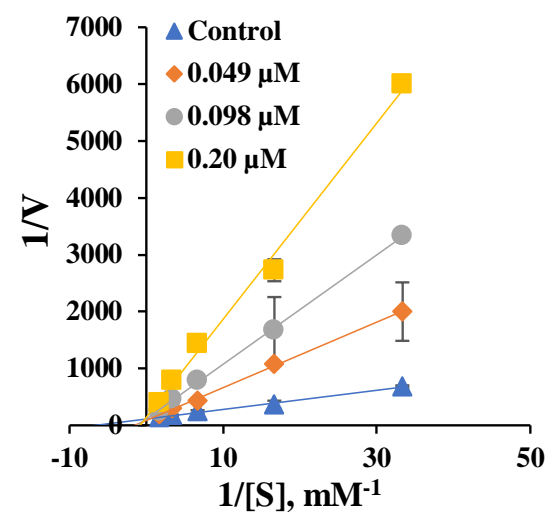

(B)

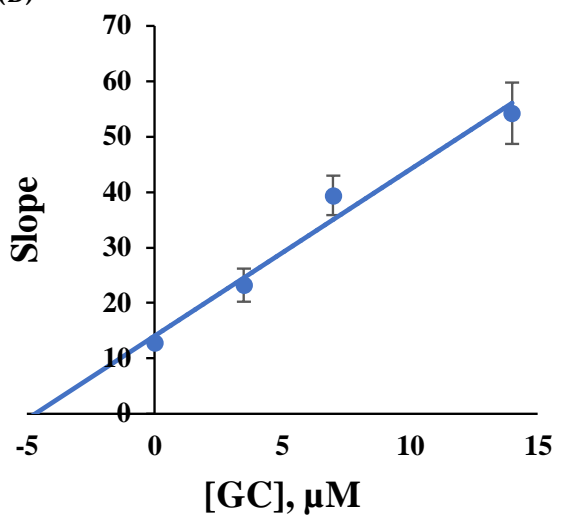

(D)

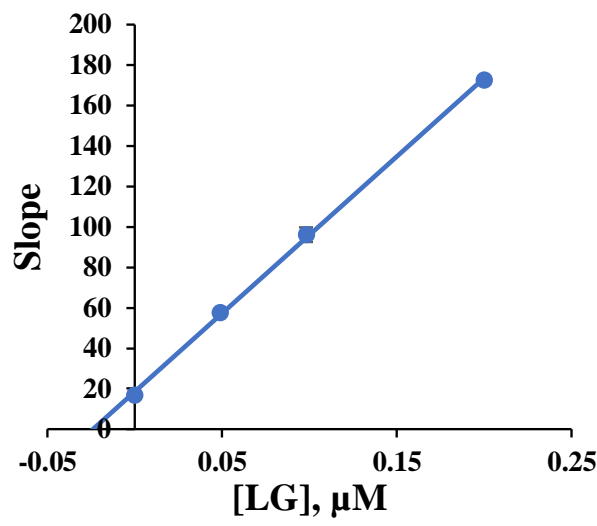

Figure 3. Lineweaver-Burk plots of inhibitions of BChE by GC (A) and of MAO-B by LG (C), and their respective secondary plots $(\mathbf{B}, \mathbf{D})$ of slopes of Lineweaver-Burk plots versus inhibitor concentrations. Five different substrate concentrations were used; $0.05,0.1,0.25,0.5$ or $1.0 \mathrm{mM}$ for BChE, and $0.03,0.06$, $0.15,0.3$, or $0.6 \mathrm{mM}$ for MAO-B. Inhibition studies were carried out at three inhibitor concentrations, that is, at $0.5 \times, 1.0 \times$, and $2.0 \times$ of the $\mathrm{IC}_{50}$ values of GC and LG. The errors were determined by duplicate experiments.

These results indicate GC acted as a noncompetitive inhibitor of BChE and bound to a site other than the understood substrate binding site of BChE. On the other hand, plots of MAO-B inhibition by LG were linear and intersected the $y$-axis (Figure 3C) and secondary plots showed the $K_{i}$ value of LG for MAO-B inhibition was $0.023 \pm 0.00061 \mu \mathrm{M}$ (Figure 3D), indicating LG is a competitive inhibitor of MAO-B.

\subsection{Molecular Docking Simulation}

Docking simulations showed that GC located at the binding site of 3-[(1S)-1-(dimethylamino)ethyl] phenol (SAF) in AChE (PDB: 1GQS) and the binding site of $N-\{[(3 R)-1-(2,3-$ dihydro-1H-inden-2-yl) piperidin-3-yl]methyl\}-N-(2-methoxyethyl)naphthalene-2-carboxamide in BChE (PDB ID: 4TPK). The binding affinity $(-7.8 \mathrm{kcal} / \mathrm{mol})$ of $\mathrm{GC}$ for $\mathrm{BChE}$ was greater than its affinity for $\mathrm{AChE}(-7.1 \mathrm{kcal} / \mathrm{mol})$ as determined by AutoDock Vina (Table 2), and these binding affinity values concurred with the $\mathrm{IC}_{50}$ values (Table 1). Docking simulation results suggested that GC did not form a hydrogen bond with AChE (Figure 4A), but that GC forms two hydrogen bonds with the Thr284 and Val288 residues of BChE (distances: 2.42 and $1.92 \AA$, respectively) (Figure 4B). These results explain the preference of GC for BChE. 
Table 2. Docking scores of GC, LG, and liquiritin with AChE, BChE, MAO-A, and MAO-B.

\begin{tabular}{ccccc}
\hline \multirow{2}{*}{ Compounds } & \multicolumn{4}{c}{ Docking Scores (kcal/mol) } \\
\cline { 2 - 5 } & AChE & BChE & MAO-A & MAO-B \\
\hline GC & -7.1 & -7.8 & - & - \\
LG & - & - & -7.9 & -8.8 \\
Liquiritin & - & - & -2.9 & -4.1 \\
\hline
\end{tabular}

The values were obtained using AutoDock Vina.

(A)

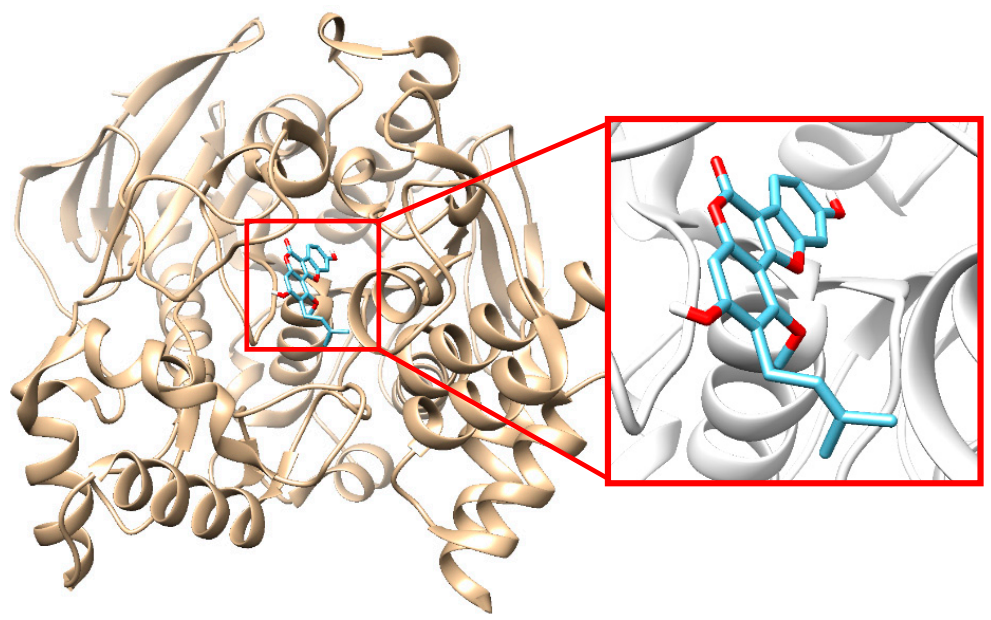

(B)

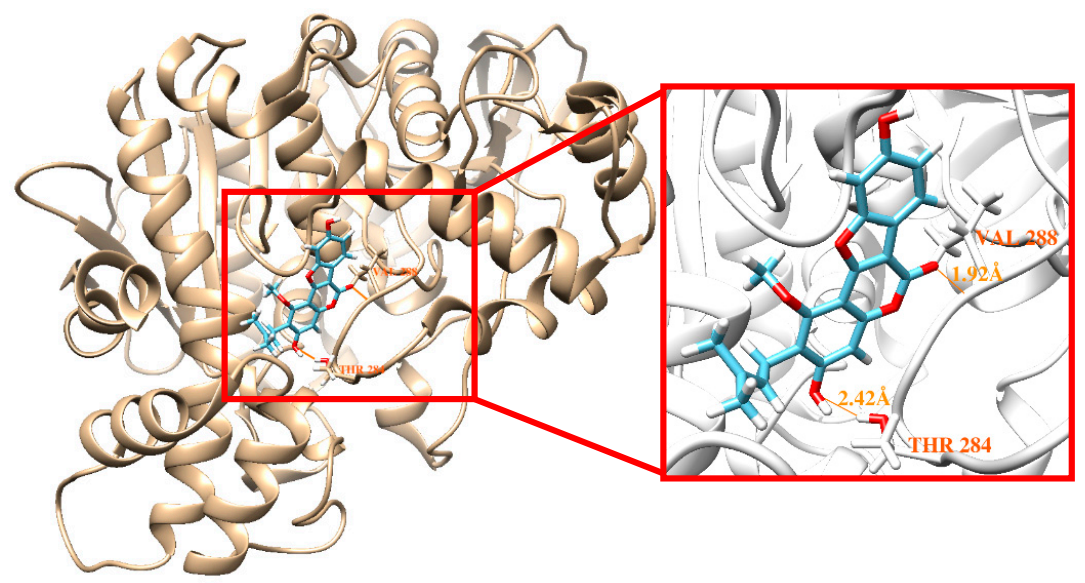

(C)

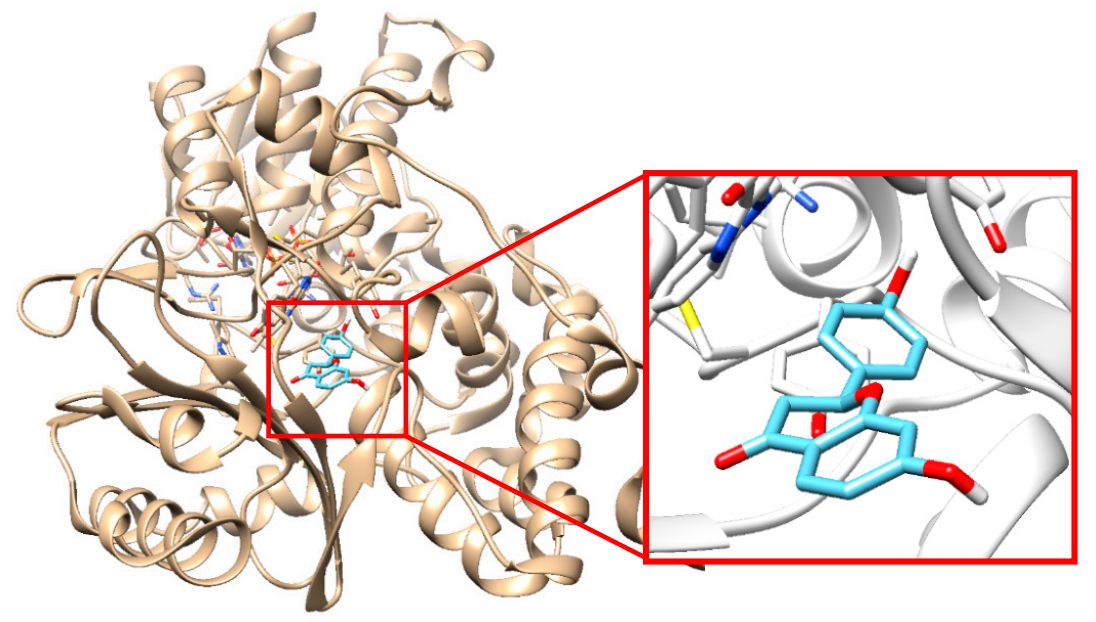

Figure 4. Cont. 
(D)

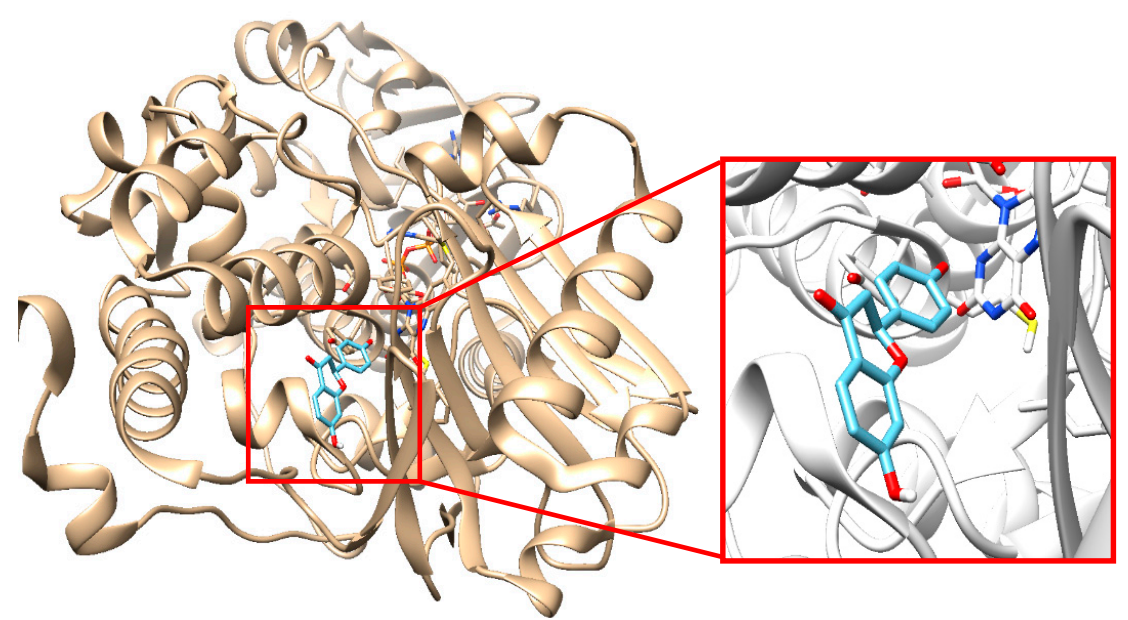

$(\mathbf{E})$

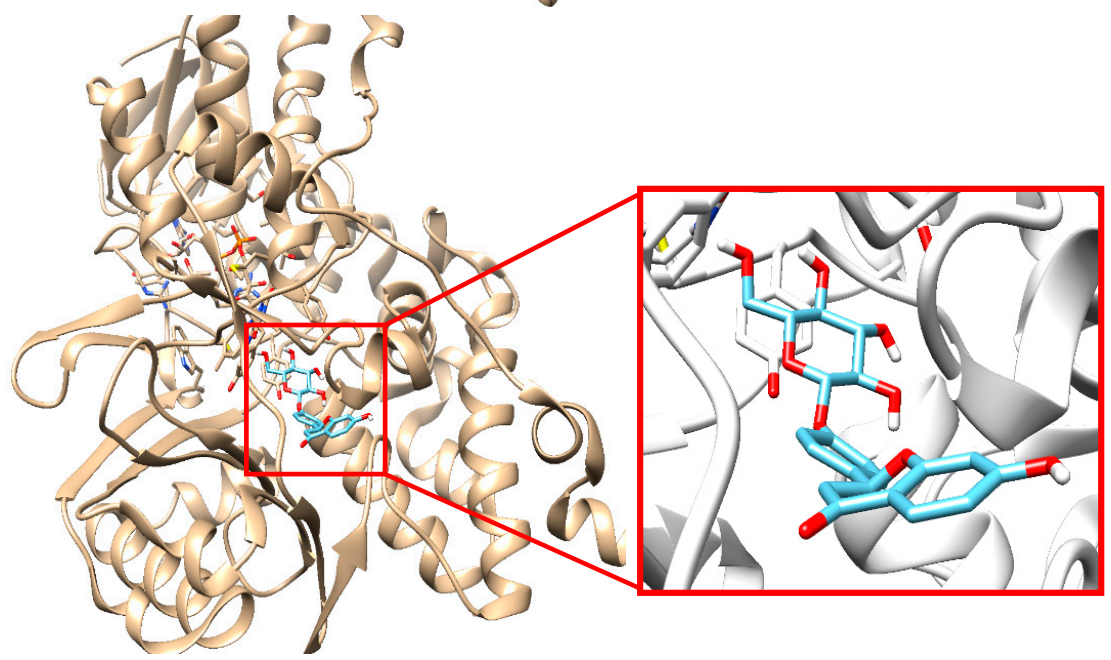

$(\mathbf{F})$

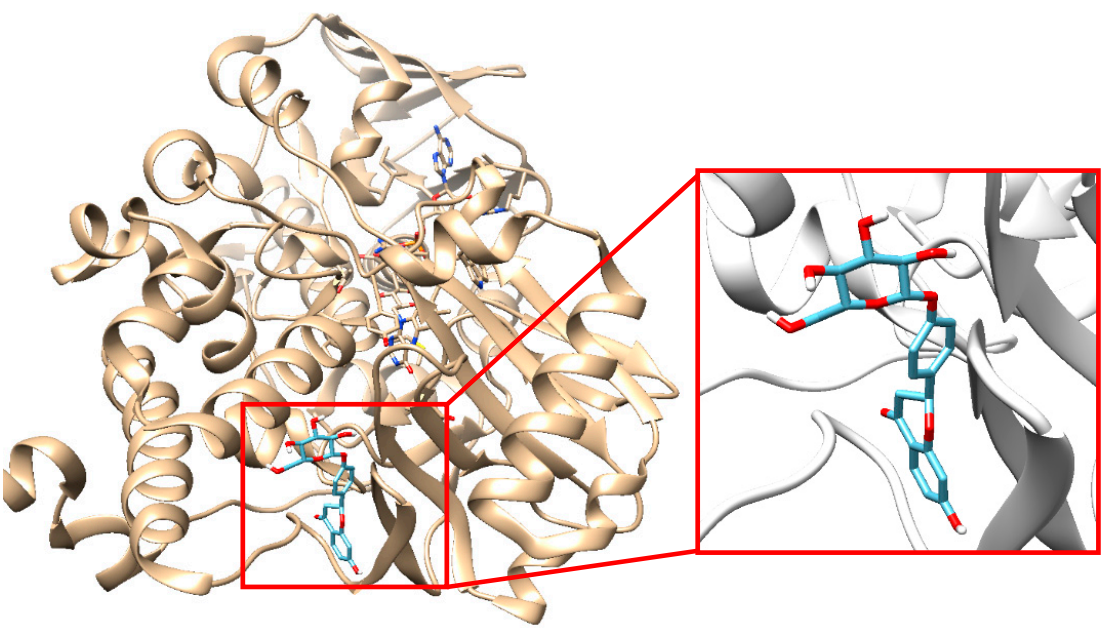

Figure 4. Docking simulations of GC with AChE (A) and BChE (B), LG with MAO-A (C) and MAO-B (D), and liquiritin with MAO-A (E) and MAO-B (F). AChE (1GQS), BChE (4TPK), MAO-A (2Z5X), and MAO-B (4A79) were subjected to docking analysis.

LG and liquiritin located at the binding site of 7-methoxy-1-methyl-9H-beta-carboline complexed with MAO-A (PDB: 2Z5X) and of pioglitazone complexed with MAO-B (PDB: 4A79). The binding affinities of LG and liquiritin with MAO-B were greater than their binding affinities with MAO-A (Table 2), and LG binding affinities were in-line with the $\mathrm{IC}_{50}$ values shown in Table 1 . However, 
docking simulations did not predict hydrogen bond formation between LG or liquiritin with MAO-A or MAO-B (Figure $4 \mathrm{C}-\mathrm{F}$ ).

\section{Discussion}

In the present study, GC (a coumarin) was isolated from G. uralensis and its BChE inhibitory activity was evaluated. Coumarins are characterized by the presence of 1,2-benzopyrone or benzopyran-2-one groups, which are the most common oxygen-containing heterocyclic compounds found in Nature. The ChE inhibitory activities by coumarins have been previously reviewed for synthetic and natural compounds [38]. Most of the known coumarins have a lower $\mathrm{IC}_{50}$ value for $\mathrm{AChE}$ than for $\mathrm{BChE}$, and selectivity for AChE or BChE is dependent on scaffold substituents, as exemplified by 3-(4-aminophenyl)-coumarin derivatives [39]. Furthermore, potencies of natural coumarins for $\mathrm{AChE}$ or BChE are much weaker than those of synthetic analogues. Nevertheless, natural coumarins exhibit significant inhibitory activities against $\mathrm{AChE}$, examples include xanthotoxin from Ferula lutea $\left(\mathrm{IC}_{50}=0.76 \mu \mathrm{M}\right)[40]$ and a 4-phenylcoumarin mesuagenin B from Mesua elegans $\left(\mathrm{IC}_{50}=0.70 \mu \mathrm{M}\right)[41]$. Based on the classification of natural $\mathrm{AChE}$ inhibitors, those with $\mathrm{IC}_{50}$ values $\leq 15 \mu \mathrm{M}$ are termed high potency inhibitors and those with values ranging from 15 to $50 \mu \mathrm{M}$ moderate potency inhibitors [42]. According to this classification, $\mathrm{GC}$ is a high potency $\mathrm{AChE}$ inhibitor $\left(\mathrm{IC}_{50}=14.77 \mu \mathrm{M}\right)$, though the value is near the threshold. In a previous study, osthenol, a prenylated coumarin obtained from Angelica pubescens, selectively inhibited MAO-A, and exhibited moderate AChE inhibitory activity $\left(\mathrm{IC}_{50}=25.3 \mu \mathrm{M}\right)[43]$.

Natural coumarins have been reported to have low BChE inhibitory activities; sphondin and pimpinellin from Heracleum platytaenium inhibited BChE by $63.69 \%$ and $78.02 \%$, respectively, at a concentration of $25 \mu \mathrm{g} / \mathrm{mL}$ concentration (115.7 and $101.5 \mu \mathrm{M}$, respectively) [44], and notably, all these $\mathrm{IC}_{50}$ values are higher than that of $\mathrm{GC}(\mathrm{IC} 50=7.22 \mu \mathrm{M})$ as determined in the present study.

As regards other natural compounds, inhibition of BChE by GC was greater than that by boldine $\left(\mathrm{IC}_{50}=321 \mu \mathrm{M}\right)$ [45], hyperforin and hyuganin $\mathrm{C}\left(\mathrm{IC}_{50}=141.60\right.$ and $38.86 \mu \mathrm{M}$, respectively) [46], cremaphenanthrene $\mathrm{F}(14.62)$ [47], scopoletin $\left(\mathrm{IC}_{50}=9.11 \mu \mathrm{M}\right)$ [48], and broussonin $\mathrm{A}$ and sagachromanol $\mathrm{I}\left(\mathrm{IC}_{50}=7.50\right.$ and $10.79 \mu \mathrm{M}$, respectively) [49], but less than those of norditerpenoids isograndifoliol and $(1 R, 15 R)-1$-acetoxycryptotanshinone $\left(\mathrm{IC}_{50}=0.9\right.$ and $2.4 \mu \mathrm{M}$, respectively) [50]. Notably, these $\mathrm{IC}_{50}$ values were much greater than those for $\mathrm{AChE}$ inhibition by tannic acid $\left(\mathrm{IC}_{50}=0.087 \mu \mathrm{M}\right)$ [51], or hesperidin $\left(\mathrm{IC}_{50}=0.00345 \mu \mathrm{M}\right)$ [52].

Dual inhibitions of ChE and MAO-B have been investigated in the context of AD [11,16]. In the present study, GC potently inhibited $\mathrm{BChE}$ with an $\mathrm{IC}_{50}$ value of $7.22 \mu \mathrm{M}$, and moderately inhibited AChE and MAO-B, indicating GC should be considered as a multi-function inhibitor of BChE, AChE, and MAO-B.

Pan et al. reported that MAO-B inhibition by LG in rat liver mitochondria was weaker than MAO-A inhibition by a mixed type [32]. However, in our study, LG more potently inhibited human MAO-B $\left(\mathrm{IC}_{50}=0.098 \mu \mathrm{M}\right)$ than human MAO-A $\left(\mathrm{IC}_{50}=0.27 \mu \mathrm{M}\right)$ and functioned as a competitive inhibitor. The $\mathrm{IC}_{50}$ of LG for MAO-B was lower than that of the flavonoid acacetin $\left(\mathrm{IC}_{50}=0.17 \mu \mathrm{M}\right)$ [53], which is one of the lowest $\mathrm{IC}_{50}$ values reported for a natural compound to date. Liquiritin was less effective than LG, aglycone of liquiritin, likely observed in acacetin and acacetin 7-O-(6-O-malonylglucoside) [53].

In our docking analysis, GC showed greater binding affinity with BChE than with AChE, and LG and liquiritin were predicted to bind to MAO-B more strongly than to MAO-A, and these results agreed well with determined $\mathrm{IC}_{50}$ values. In particular, our kinetic study showed that GC noncompetitively inhibited BChE. Docking simulation was performed to identify BChE binding sites. The docked pose for GC indicated that it interacted with BChE beyond the active site and hydrogen bonded with Thr284 and Val288. The active-site of BChE is composed of 4 subdomains, i.e., a peripheral site, a choline binding pocket, a catalytic site, and an acyl binding pocket [54], and the acyl binding pocket contains Trp231, Leu286, and Val288, which permit binding and hydrolysis of ligands and substrates bulkier than those of AChE [54], which is considered to be largely responsible for the different 
ligand-binding specificities of $\mathrm{AChE}$ and BChE [55]. Jannat et al. reported that (2S,3R)-pretosin C is a noncompetitive inhibitor of BChE and that it hydrophobically interacts with Val288, Lue286, and Phe357, and hydrogen bonds with Gly283 and Asn397, and docks at a non-ligand binding site [56]. It was also observed that hydrogen bond formation was the main driving force behind BChE-coumarin complex formation, whereas hydrophobic and halogen interactions underpinned AChE interactions with N1-(coumarin-7-yl) derivatives [57]. Similarly, we found that GC hydrogen bonded with Thr284 and Val288 located outside the ligand binding site. Such results suggest that GC might bind noncompetitively at the acyl binding pocket of $\mathrm{BChE}$.

\section{Materials and Methods}

\subsection{General}

The dried roots of Glycyrrhiza uralensis were purchased in April 2011 at a commercial herbal market (Human-herb, Gyeongsan, Gyeongbuk, South Korea). Organic solvents (e.g., methanol (MeOH), chloroform $\left(\mathrm{CHCl}_{3}\right)$, methylene chloride (MC), ethyl acetate (EtOAc), and $n$-hexane (Hx)) were purchased from Duksan Chemical Co. (Seoul, South Korea). Column chromatography was performed using silica gel 60 (70-230 mesh, 230-400 mesh, ASTM, Merck, Darmstadt, Germany), octadecyl silica gel (ODS-A, $12 \mathrm{~nm}$, S-150 m, YMC, Tokyo, Japan), and Sephadex LH-20 gel (GE Healthcare, Uppsala, Sweden). NMR spectra were recorded on a JEOL ECX-500 spectrometer, operating at $500 \mathrm{MHz}$ for ${ }^{1} \mathrm{H}$ - and $125 \mathrm{MHz}$ for ${ }^{13} \mathrm{C}-\mathrm{NMR}$ (JEOL Ltd., Tokyo, Japan). High performance liquid chromatography (HPLC) was performed using an Agilent 1260 series system (Agilent Inc., Palo Alto, CA, USA) equipped with a binary pump, an autosampler, a column oven, a Phenomenex Kinetex C18 column $(2.6 \mu \mathrm{m}, 150 \times 4.6 \mathrm{~mm}$; Phenomenex, Torrance, CA, USA), a photodiode array detector (DAD), and an evaporative light scattering detector (ELSD). Trifluoroacetic acid (TFA, $0.1 \%, v / v$ ) was used in water (solvent $\mathrm{A}$ ) and in acetonitrile (ACN; solvent $\mathrm{B}$ ). Gradient was applied to the elution from $95 \%$ $\mathrm{A} / 5 \% \mathrm{~B}(0-3 \mathrm{~min})$ to $0 \% \mathrm{~A} / 100 \% \mathrm{~B}(3-30 \mathrm{~min})$ at $0.5 \mathrm{~mL} / \mathrm{min}$ using $3 \mu \mathrm{L}$ of injection volume.

\subsection{Extraction and Isolation of Coumarin Derivatives}

The dried roots of Glycyrrhiza uralensis $(1 \mathrm{~kg})$ were extracted with $\mathrm{MeOH}$ at room temperature for $24 \mathrm{~h}(3 \times 10 \mathrm{~L})$ to obtain a crude MEOH extract, and $110 \mathrm{~g}$ of this extract was then suspended in $2000 \mathrm{~mL}$ of distilled water and partitioned versus the same volume of $\mathrm{CHCl}_{3}$ and $\mathrm{EtOAc}$. The $\mathrm{CHCl}_{3}$ extract ( $25.2 \mathrm{~g}$ ) obtained was separated into five fractions (GHC 1-5) by silica gel column chromatography using a $\mathrm{Hx}$ and EtOAc gradient (30:1 to 1:1). GHC 3 (5.2 g) was then separated by silica column chromatography using an $\mathrm{Hx}$ and EtOAc gradient (1:0 to 0:1) to yield ten subfractions (GHC 3-1-3-10). Subfraction GHC 3-5 (1.1 g) was subjected to reverse-phase column chromatography using ODS-A gel $(50 \%$ aqueous $\mathrm{MeOH}, v / v)$ to obtain GC $(\mathbf{1}, 261.0 \mathrm{mg}$, purity: $99 \%)$. Subfraction GHC 3-7 was subjected to reverse-phase column chromatography using ODS-A gel $(60 \%$ aqueous $\mathrm{MeOH}, v / v)$ to obtained isoliquiritin (2,372.0 mg, purity: $98.3 \%)$. Pure LG (3, $530 \mathrm{mg}$, purity: $99 \%)$ was obtained from fraction GHC 4 using silica gel column chromatography with an Hx and EtOAc gradient (15:1 to 5:1). In addition, the EtOAc soluble extract (16.7 g) was separated into nine fractions (GHE 1-9) by silica gel column chromatography using an MC and MeOH gradient (40:1 to 4:1). Fraction GHE 2 (1.2 g) was separated by silica column chromatography using an $\mathrm{Hx}$ and EtOAc gradient (10:1) to obtain glycyrrhetinic acid (4, $113 \mathrm{mg}$, purity: 99\%). Fraction GHE $6(0.9 \mathrm{~g})$ was subjected to silica gel column chromatography using an $\mathrm{MC}$ and $\mathrm{MeOH}$ gradient (15:1 to 6:1) to obtain liquiritin (5, 128.0 $\mathrm{mg}$, purity: 99\%). Fraction GHE 9 (3.6 g) was isolated by reverse-phase column chromatography using ODS-A gel $(40 \%$ aqueous $\mathrm{MeOH}, v / v)$ to yield four fractions (GHE 9-1 9-4). Subsequently, subfraction GHE 9-3 was subjected to silica gel column chromatography using an isocratic MC-EtOAc-MeOH (3.5:3.5:1) mixture to obtain liquiritin apioside $(6,70.0 \mathrm{mg}$, purity: $95.1 \%)$. The water-soluble extract $(20.2 \mathrm{~g})$ was separated into five fractions (GHD 1-5) by chromatography on an LH-20 gel column using a $\mathrm{H}_{2} \mathrm{O}$ and $\mathrm{MeOH}$ gradient (0:1 to 1:1). Fraction GHD 4 (12.6 g) was separated by reverse-phase column 
chromatography using a $\mathrm{MeOH}$ and $\mathrm{H}_{2} \mathrm{O}$ gradient (5:6 to 3:2, v/v) to yield seven fractions (GHD 4-1-4-7). Subfraction GHD 4-5 was subjected to silica column chromatography using a $\mathrm{CHCl}_{3}-\mathrm{MeOH}$ (4:1) as eluent and yielded isoliquiritin apioside $(7,35.0 \mathrm{mg}$, purity: $96.3 \%)$. Glycyrrhizin was obtained from hot water extracts. The hot water extracts $(28.1 \mathrm{~g})$ was aggregated by reducing its $\mathrm{pH}$ to 2.0 with $10 \% \mathrm{H}_{2} \mathrm{SO}_{4}$ and filtering through Whatman No. 1 paper. The precipitate obtained was suspended in distilled water $(1000 \mathrm{~mL})$, the $\mathrm{pH}$ was adjusted to 7.0 using ammonia water, and glycyrrhizin (8, $223.0 \mathrm{mg}$, purity: $99 \%$ ) was obtained by subjecting this solution to ODS-A gel column chromatography using $60 \%$ aqueous ACN as eluant. HPLC chromatograms of the eight compounds were provided in Supplementary Figure S1.

\subsection{Chemicals and Enzyme Assays}

Enzymes (recombinant human MAO-A and MAO-B, AChE from Electrophorus electricus, and BChE from equine serum), substrates (kynuramine and benzylamine, acetylthiocholine iodide (ATCI), S-butyrylthiocholine iodide (BTCI)), inhibitors (toloxatone, lazabemide, and tacrine), and other chemicals including 5,5'-dithiobis(2-nitrobenzoic acid) (DTNB) were purchased from Sigma-Aldrich (St. Louis, MO, USA) [49,58]. The irreversible inhibitors (clorgyline and pargyline) were obtained from BioAssay Systems (Hayward, CA, USA) [59].

MAO-A and MAO-B activities were measured continuously at $316 \mathrm{~nm}$ for $20 \mathrm{~min}$, and at $250 \mathrm{~nm}$ for $30 \mathrm{~min}$, respectively, as described previously $[60,61]$. The concentrations used were; kynuramine $(0.06 \mathrm{mM})$ for MAO-A and benzylamine $(0.3 \mathrm{mM})$ for MAO-B. AChE activity was assayed continuously for $10 \mathrm{~min}$ at $412 \mathrm{~nm}$ using $0.2 \mathrm{U} / \mathrm{mL}$ of enzyme in the presence of $0.5 \mathrm{mM}$ DTNB and $0.5 \mathrm{mM}$ ATCI in $0.5 \mathrm{~mL}$ of reaction mixture, as previously described $[49,58]$, based on the method developed by Ellman et al. [62]. BChE activity was assayed using the same method as AChE, except using BTCI [49]. Substrate concentrations of BTCI for $\mathrm{BChE}$ and benzylamine for MAO-B were 2.3- and 2.1-fold of the respective $\mathrm{K}_{\mathrm{m}}$ values $(0.22$ and $0.14 \mathrm{mM})$.

\subsection{Inhibitory Activities and Enzyme kinetics}

Inhibitions of MAO-A, MAO-B, AChE, and $\mathrm{BChE}$ were initially observed at an inhibitor concentration of $10 \mu \mathrm{M}$. IC 50 values of compounds exhibiting $>50 \%$ inhibition were determined. Kinetic parameters, inhibition types, and $K_{i}$ values were determined for the most potent inhibitors, i.e., GC for BChE and LG for MAO-B, as previously described [49,58]. The kinetics of BChE and MAO-B inhibitions were investigated at five different substrate concentrations; $0.05,0.1,0.25,0.5$ or 1.0 $\mathrm{mM}$ for BChE, and $0.03,0.06,0.15,0.3$, or $0.6 \mathrm{mM}$ for MAO-B. Inhibition studies were conducted in the absence or presence of each inhibitor at about $0.5 \times, 1.0 \times$, and $2.0 \times$ their $\mathrm{IC}_{50}$ values [58]. Inhibitory patterns and $\mathrm{K}_{\mathrm{i}}$ values were determined using Lineweaver-Burk plots and secondary derivative plots.

\subsection{Analysis of Inhibitor Reversibility}

The reversibilities of BChE inhibition by GC and of MAO-B inhibition by LG were investigated by dialysis at concentrations of $2 \times \mathrm{IC}_{50}$ values, as previously described [63]. After preincubating GC or LG with BChE or MAO-B, respectively, for $30 \mathrm{~min}$, residual activities for undialyzed and $6 \mathrm{~h}$-dialyzed samples were measured; relative values for $A_{U}$ and $A_{D}$ were then calculated and compared with each control without inhibitor. Reversibilities were determined by comparing $A_{U}$ and $A_{D}$ values of inhibitors with those of references. In addition, the dilution method was used to access BChE activity recovery after inhibition by GC (i.e., after preincubating $\mathrm{BChE}$ with $\mathrm{GC}$ at $50 \times \mathrm{IC}_{50}$ for $15 \mathrm{~min}$ ) and diluting to a GC concentration of $1 \times \mathrm{IC}_{50}$ [60]. Residual activity of the preincubated and then diluted mixture was measured and compared to those of mixtures at $1 \times$ or $50 \times \mathrm{IC}_{50}$ concentrations.

\subsection{Docking Simulations of GC with $A C h E$ and BChE and of $L G$ or Liquiritin with MAO-A and MAO-B}

To simulate docking of GC with AChE or BChE, we used Autodock Vina [64], which has an automated docking facility. To define enzyme docking pockets, we used a set of predefined active 
sites defined using a complex of AChE with 3-[(1S)-1-(dimethylamino)ethyl]phenol (SAF) (PDB ID: 1GQS) or a complex of BChE with $N$-\{[(3R)-1-(2,3-dihydro-1H-inden-2-yl)piperidin-3-yl]methyl $\}$ - $N$-(2-methoxyethyl) naphthalene-2-carboxamide (3F9) (PDB ID: 4TPK). In addition, to define MAO-A or MAO-B docking sites with LG or liquiritin, we used a set of predefined active sites obtained using MAO-A/7-methoxy-1-methyl-9H- $\beta$-carboline complex (PDB ID: 2Z5X) or MAO-B/pioglitazone complex (PDB ID: 4A79). To prepare for docking simulations, we performed the following steps: created 2D structures, converted 2D into 3D structures, performed energy minimization using the ChemOffice program (http://www.cambridgesoft.com) and docking simulations using Chimera [65], and checked for possible hydrogen bonding interactions using $0.4 \AA$ and $20.0^{\circ}$ constraints using Chimera [66].

\section{Conclusions}

GC effectively inhibited $\mathrm{BChE}$ and $\mathrm{AChE}\left(\mathrm{IC}_{50}=7.22\right.$ and $14.77 \mu \mathrm{M}$, respectively), and also moderately inhibited MAO-B $\left(\mathrm{IC}_{50}=29.48 \mu \mathrm{M}\right)$. LG potently inhibited MAO-B $\left(\mathrm{IC}_{50}=0.098 \mu \mathrm{M}\right)$ and MAO-A $\left(\mathrm{IC}_{50}=0.27 \mu \mathrm{M}\right)$. GC was found to be a noncompetitive inhibitor of BChE and LG to be a competitive inhibitor of MAO-B. The binding affinity of GC for BChE $(-7.8 \mathrm{kcal} / \mathrm{mol})$ was higher than its affinity for $\mathrm{AChE}(-7.1 \mathrm{kcal} / \mathrm{mol})$, and this binding was driven by hydrogen bond formation with Thr284 and Val288 of BChE. These findings regarding the multi-inhibitory effects of GC and LG suggest that they be considered potential candidates for the treatment of Alzheimer's disease.

Supplementary Materials: ${ }^{1} \mathrm{H}$ - and ${ }^{13} \mathrm{C}-\mathrm{NMR}$ spectral data are available in the Supplementary Materials.

Author Contributions: Conceptualization: M.C. and H.K.; biological activity: G.S.J. and S.R.L.; kinetics: G.S.J. and S.R.L.; compound isolation and identification: J.Y.L. and M.C.; docking analysis: M.-G.K. and D.P.; original draft writing: G.S.J., M.-G.K. and J.Y.L.; review and editing: D.P., M.C., and H.K.; supervision: H.K.; funding acquisition: H.K. All authors have read and agreed to the published version of the manuscript.

Funding: This study was supported by the Cooperative Research Program for Agriculture Science and Technology Development (\#PJ01319104) of the Rural Development Administration, Republic of Korea.

Conflicts of Interest: The authors have no conflict of interest to declare.

\section{References}

1. Bierer, L.M.; Haroutunian, V.; Gabriel, S.; Knott, P.J.; Carlin, L.S.; Purohit, D.P.; Perl, D.P.; Schmeidler, J.; Kanof, P.; Davis, K.L. Neurochemical correlates of dementia severity in Alzheimer's disease: Relative importance of the cholinergic deficits. J. Neurochem. 1995, 64, 749-760. [CrossRef] [PubMed]

2. Colović, M.B.; Krstić, D.Z.; Lazarević-Pašti, T.D.; Bondžić, A.M.; Vasić, V.M. Acetylcholinesterase inhibitors: Pharmacology and toxicology. Curr. Neuropharmacol. 2013, 11, 315-335. [CrossRef] [PubMed]

3. Anand, P.; Singh, B. A review on cholinesterase inhibitors for Alzheimer's disease. Arch. Pharm. Res. 2013, 36, 375-399. [CrossRef] [PubMed]

4. Ghai, R.; Nagarajan, K.; Arora, M.; Grover, P.; Ali, N.; Kapoor, G. Current strategies and novel drug approaches for Alzheimer disease. CNS Neurol. Disord. Drug Targets 2020. [CrossRef] [PubMed]

5. Kumar, A.; Pintus, F.; Di Petrillo, A.; Medda, R.; Caria, P.; Matos, M.J.; Vina, D.; Pieroni, E.; Delogu, F.; Era, B.; et al. Novel 2-phenylbenzofuran derivatives as selective butyrylcholinesterase inhibitors for Alzheimer's disease. Sci. Rep. 2018, 8, 4424. [CrossRef]

6. Korábečný, J.; Nepovimová, E.; Cikánková, T.; Špilovská, K.; Vašková, L.; Mezeiová, E.; Kuča, K.; Hroudová, J. Newly developed drugs for Alzheimer's disease in relation to energy metabolism, cholinergic and monoaminergic neurotransmission. Neuroscience 2018, 370, 191-206. [CrossRef]

7. Lake, F. BChE reported to be associated with plaque level in Alzheimer's disease. Biomark. Med. 2013, 7, 197-198.

8. Ramsay, R.R. Monoamine oxidases: The biochemistry of the proteins as targets in medicinal chemistry and drug discovery. Curr. Top. Med. Chem. 2012, 12, 2189-2209. [CrossRef]

9. Youdim, M.B.; Edmondson, D.; Tipton, K.F. The therapeutic potential of monoamine oxidase inhibitors. Nat. Rev. Neurosci. 2006, 7, 295-309. [CrossRef] 
10. Schedin-Weiss, S.; Inoue, M.; Hromadkova, L.; Teranishi, Y.; Yamamoto, N.G.; Wiehager, B.; Bogdanovic, N.; Winblad, B.; Sandebring-Matton, A.; Frykman, S.; et al. Monoamine oxidase B is elevated in Alzheimer disease neurons, is associated with $\gamma$-secretase and regulates neuronal amyloid $\beta$-peptide levels. Alzheimers Res. Ther. 2017, 9, 57. [CrossRef]

11. Ramsay, R.R.; Tipton, K.F. Assessment of enzyme inhibition: A review with examples from the development of monoamine oxidase and cholinesterase inhibitory drugs. Molecules 2017, 22, 1192. [CrossRef] [PubMed]

12. Li, Y.; Qiang, X.; Luo, L.; Yang, X.; Xiao, G.; Zheng, Y.; Cao, Z.; Sang, Z.; Su, F.; Deng, Y. Multitarget drug design strategy against Alzheimer's disease: Homoisoflavonoid mannich base derivatives serve as acetylcholinesterase and monoamine oxidase B dual inhibitors with multifunctional properties. Bioorg. Med. Chem. 2017, 25, 714-726. [CrossRef] [PubMed]

13. Cai, P.; Fang, S.Q.; Yang, H.L.; Yang, X.L.; Liu, Q.H.; Kong, L.Y.; Wang, X.B. Donepezil-butylated hydroxytoluene (BHT) hybrids as anti-Alzheimer's disease agents with cholinergic, antioxidant, and neuroprotective properties. Eur. J. Med. Chem. 2018, 157, 161-176. [CrossRef] [PubMed]

14. He, Q.; Liu, J.; Lan, J.S.; Ding, J.; Sun, Y.; Fang, Y.; Jiang, N.; Yang, Z.; Sun, L.; Jin, Y.; et al. Coumarin-dithiocarbamate hybrids as novel multitarget AChE and MAO-B inhibitors against Alzheimer's disease: Design, synthesis and biological evaluation. Bioorg. Chem. 2018, 81, 512-528. [CrossRef]

15. Pisani, L.; Iacobazzi, R.M.; Catto, M.; Rullo, M.; Farina, R.; Denora, N.; Cellamare, S.; Altomare, C.D. Investigating alkyl nitrates as nitric oxide releasing precursors of multitarget acetylcholinesterase-monoamine oxidase B inhibitors. Eur. J. Med. Chem. 2019, 161, 292-309. [CrossRef]

16. Oh, J.M.; Rangarajan, T.M.; Chaudhary, R.; Singh, R.P.; Singh, M.; Singh, R.P.; Tondo, A.R.; Gambacorta, N.; Nicolotti, O.; Mathew, B.; et al. Novel class of chalcone oxime ethers as potent monoamine oxidase-B and acetylcholinesterase inhibitors. Molecules 2020, 25, 2356. [CrossRef]

17. Mascarenhas, A.M.S.; de Almeida, R.B.M.; de Araujo Neto, M.F.; Mendes, G.O.; da Cruz, J.N.; Dos Santos, C.B.R.; Botura, M.B.; Leite, F.H.A. Pharmacophore-based virtual screening and molecular docking to identify promising dual inhibitors of human acetylcholinesterase and butyrylcholinesterase. J. Biomol. Struct. Dyn. 2020. [CrossRef]

18. Uddin, M.S.; Kabir, M.T.; Rahman, M.M.; Mathew, B.; Shah, M.A.; Ashraf, G.M. TV 3326 for Alzheimer's dementia: A novel multimodal $\mathrm{ChE}$ and MAO inhibitors to mitigate Alzheimer's-like neuropathology. J. Pharm. Pharmcol. 2020, 72, 1001-1012. [CrossRef]

19. Purgatorio, R.; Kulikova, L.; Pisani, L.; Catto, M.; de Candia, M.; Carrieri, A.; Cellamare, S.; De Palma, A.; Beloglazkin, A.; Raesi, G.R.; et al. Scouting around 1,2,3,4-Tetrahydrochromeno[3,2-c]pyridin-10-ones for single- and multi-target ligands directed towards relevant Alzheimer's targets. ChemMedChem 2020. [CrossRef]

20. Lee, S.; Oh, H.M.; Lim, W.B.; Choi, E.J.; Park, Y.N.; Kim, J.A.; Choi, J.Y.; Hong, S.J.; Oh, H.K.; Son, J.K.; et al. Gene induction by glycyrol to apoptosis through endonuclease $\mathrm{G}$ in tumor cells and prediction of oncogene function by microarray analysis. Anticancer Drugs 2008, 19, 503-515. [CrossRef]

21. Xu, M.Y.; Kim, Y.S. Antitumor activity of glycyrol via induction of cell cycle arrest, apoptosis and defective autophagy. Food Chem. Toxicol. 2014, 74, 311-319. [CrossRef] [PubMed]

22. Lu, S.; Ye, L.; Yin, S.; Zhao, C.; Yan, M.; Liu, X.; Cui, J.; Hu, H. Glycyrol exerts potent therapeutic effect on lung cancer via directly inactivating T-LAK cell-originated protein kinase. Pharmacol. Res. 2019, 147, 104366. [CrossRef] [PubMed]

23. Rhew, Z.I.; Han, Y. Synergic effect of combination of glycyrol and fluconazole against experimental cutaneous candidiasis due to Candida albicans. Arch. Pharm. Res. 2016, 39, 1482-1489. [CrossRef] [PubMed]

24. Tanaka, Y.; Kikuzaki, H.; Fukuda, S.; Nakatani, N. Antibacterial compounds of licorice against upper airway respiratory tract pathogens. J. Nutr. Sci. Vitaminol. 2001, 47, 270-273. [CrossRef]

25. Ryu, Y.B.; Kim, J.H.; Park, S.J.; Chang, J.S.; Rho, M.C.; Bae, K.H.; Park, K.H.; Lee, W.S. Inhibition of neuraminidase activity by polyphenol compounds isolated from the roots of Glycyrrhiza uralensis. Bioorg. Med. Chem. Lett. 2010, 20, 971-974. [CrossRef]

26. Adianti, M.; Aoki, C.; Komoto, M.; Deng, L.; Shoji, I.; Wahyuni, T.S.; Lusida, M.I.; Fuchino, H.; Kawahara, N.; Hotta, H. Anti-hepatitis C virus compounds obtained from Glycyrrhiza uralensis and other Glycyrrhiza species. Microbiol. Immunol. 2014, 58, 180-187. [CrossRef] 
27. Shin, E.M.; Zhou, H.Y.; Guo, L.Y.; Kim, J.A.; Lee, S.H.; Merfort, I.; Kang, S.S.; Kim, H.S.; Kim, S.; Kim, Y.S. Anti-inflammatory effects of glycyrol isolated from Glycyrrhiza uralensis in LPS-stimulated RAW264.7 macrophages. Int. Immunopharmacol. 2008, 8, 1524-1532. [CrossRef]

28. Fu, Y.; Zhou, H.; Wang, S.; Wei, Q. Glycyrol suppresses collagen-induced arthritis by regulating autoimmune and inflammatory responses. PLoS ONE 2014, 9, e98137. [CrossRef]

29. Bai, H.; Bao, F.; Fan, X.; Han, S.; Zheng, W.; Sun, L.; Yan, N.; Du, H.; Zhao, H.; Yang, Z. Metabolomics study of different parts of licorice from different geographical origins and their anti-inflammatory activities. J. Sep. Sci. 2020, 43, 1593-1602. [CrossRef]

30. Li, J.; Tu, Y.; Tong, L.; Zhang, W.; Zheng, J.; Wei, Q. Immunosuppressive activity on the murine immune responses of glycyrol from Glycyrrhiza uralensis via inhibition of calcineurin activity. Pharm. Biol. 2010, 48, 1177-1184. [CrossRef]

31. Tanaka, S.; Kuwai, Y.; Tabata, M. Isolation of monoamine oxidase inhibitors from Glycyrrhiza uralensis roots and the structure-activity relationship. Planta Med. 1987, 53, 5-8. [CrossRef] [PubMed]

32. Pan, X.; Kong, L.D.; Zhang, Y.; Cheng, C.H.K.; Tan, R.X. In vitro inhibition of rat monoamine oxidase by liquiritigenin and isoliquiritigenin isolated from Sinofranchetia chinensis. Acta Pharmacol. Sin. 2000, 21, 949-953. [PubMed]

33. Lee, J.S.; Kim, J.A.; Cho, S.H.; Son, A.R.; Jang, T.S.; So, M.S.; Chung, S.R.; Lee, S.H. Tyrosinase inhibitors isolated from the roots of Glycyrrhiza glabra L. Korean J. Pharmacogn. 2003, 34, 33-39.

34. Maatooq, G.T.; Marzouk, A.M.; Gray, A.I.; Rosazza, J.P. Bioactive microbial metabolites from glycyrrhetinic acid. Phytochemistry 2010, 71, 262-270. [CrossRef] [PubMed]

35. Montoro, P.; Maldini, M.; Russo, M.; Postorino, S.; Piacente, S.; Pizza, C. Metabolic profiling of roots of liquorice (Glycyrrhiza glabra) from different geographical areas by ESI/MS/MS and determination of major metabolites by LC-ESI/MS and LC-ESI/MS/MS. J. Pharm. Biomed. Anal. 2011, 54, 535-544. [CrossRef] [PubMed]

36. Wang, H.G.; Liu, Y.N.; Le, X.Y.; Wang, S.F. Study on active constituents from Glycyrrhizae Radix et Rhizoma against NO production in LPS-induced Raw 264.7 macrophages. Chin. Tradit. Herb. Drugs 2016, 47, 4155-4159.

37. Chaturvedula, V.S.P.; Yu, O.; Mao, G. NMR analysis and hydrolysis studies of glycyrrhizin acid, a major constituent of Glycyrrhia glabra. Eur. Chem. Bull. 2014, 3, 104-107.

38. de Souza, L.G.; Renn, M.N.; Figueroa-Villar, J.D. Coumarins as cholinesterase inhibitors: A review. Chem. Biol. Interact. 2016, 254, 11e23. [CrossRef]

39. Hu, Y.H.; Yang, J.; Zhang, Y.; Liu, K.C.; Liu, T.; Sun, J.; Wang, X.J. Synthesis and biological evaluation of 3-(4-aminophenyl)-coumarin derivatives as potential anti-Alzheimer's disease agents. J. Enzym. Inhib. Med. Chem. 2019, 34, 1083-1092. [CrossRef]

40. Salem, S.B.; Jabrane, A.; Harzallah-Skhiri, F.; Jannet, H.B. New bioactive dihydrofuranocoumarins from the roots of the Tunisian Ferula lutea (Poir.) maire. Bioorg. Med. Chem. Lett. 2013, 23, 4248-4252. [CrossRef]

41. Awang, K.; Chan, G.; Litaudon, M.; Ismail, N.H.; Martin, M.T.; Gueritte, F. 4-Phenylcoumarins from Mesua elegans with acetylcholinesterase inhibitory activity. Bioorg. Med. Chem. 2010, 18, 7873-7877. [CrossRef] [PubMed]

42. Dos Santos, T.C.; Gomes, T.; Pinto, B.A.S.; Camara, A.L.; de Andrade Paes, A.M. Naturally occurring acetylcholinesterase inhibitors and their potential use for Alzheimer's disease therapy. Front. Pharmacol. 2018, 9, 1192. [CrossRef] [PubMed]

43. Baek, S.C.; Kang, M.G.; Park, J.E.; Lee, J.P.; Lee, H.; Ryu, H.W.; Park, C.M.; Park, D.; Cho, M.L.; Oh, S.R.; et al. Osthenol, a prenylated coumarin, as a monoamine oxidase A inhibitor with high selectivity. Bioorg. Med. Chem. Lett. 2019, 29, 839-843. [CrossRef] [PubMed]

44. Dincel, D.; Hatipoglu, S.D.; Gæren, A.C.; Topçu, G. Anticholinesterase furocoumarins from heracleumplatytaenium, a species endemic to the Ida mountains. Turk. J. Chem. 2013, 37, 675e683.

45. Kostelnik, A.; Pohanka, M. Inhibition of acetylcholinesterase and butyrylcholinesterase by a plant secondary metabolite boldine. Biomed. Res. Int. 2018, 2018, 9634349. [CrossRef]

46. Orhan, I.E.; Senol Deniz, F.S.; Traedal-Henden, S.; Cerón-Carrasco, J.P.; den Haan, H.; Peña-García, J.; Pérez-Sánchez, H.; Emerce, E.; Skalicka-Wozniak, K. Profiling auspicious butyrylcholinesterase inhibitory activity of two herbal molecules: Hyperforin and hyuganin C. Chem. Biodivers. 2019, 16, e1900017. [CrossRef] 
47. Liu, L.; Yin, Q.M.; Gao, Q.; Li, J.; Jiang, Y.; Tu, P.F. New biphenanthrenes with butyrylcholinesterase inhibitory activity from Cremastra appendiculata. Nat. Prod. Res. 2019, 1-7. [CrossRef]

48. Kashyap, P.; Ram, H.; Shukla, S.D.; Kumar, S. Scopoletin: Antiamyloidogenic, anticholinesterase, and neuroprotective potential of a natural compound present in argyreia speciosa roots by in vitro and in silico study. Neurosci. Insights 2020, 15, 2633105520937693. [CrossRef]

49. Lee, J.P.; Kang, M.G.; Lee, J.Y.; Oh, J.M.; Baek, S.C.; Leem, H.H.; Park, D.; Cho, M.L.; Kim, H. Potent inhibition of acetylcholinesterase by sargachromanol I from Sargassum siliquastrum and by selected natural compounds. Bioorg. Chem. 2019, 89, 103043. [CrossRef]

50. Ślusarczyk, S.; Senol Deniz, F.S.; Abel, R.; Pecio, Ł.; Pérez-Sánchez, H.; Cerón-Carrasco, J.P.; den-Haan, H.; Banerjee, P.; Preissner, R.; Krzyżak, E.; et al. Norditerpenoids with selective anti-cholinesterase activity from the roots of perovskia atriplicifolia benth. Int. J. Mol. Sci. 2020, 21, 4475. [CrossRef]

51. Türkan, F.; Taslimi, P.; Saltan, F.Z. Tannic acid as a natural antioxidant compound: Discovery of a potent metabolic enzyme inhibitor for a new therapeutic approach in diabetes and Alzheimer's disease. J. Biochem. Mol. Toxicol. 2019, 33, e22340. [CrossRef] [PubMed]

52. Taslimi, P.; Caglayan, C.; Gulcin, İ. The impact of some natural phenolic compounds on carbonic anhydrase, acetylcholinesterase, butyrylcholinesterase, and $\alpha$-glycosidase enzymes: An antidiabetic, anticholinergic, and antiepileptic study. Biochem. Mol. Toxicol. 2017. [CrossRef] [PubMed]

53. Lee, H.W.; Ryu, H.W.; Baek, S.C.; Kang, M.G.; Park, D.; Han, H.Y.; An, J.H.; Oh, S.R.; Kim, H. Potent inhibitions of monoamine oxidase $\mathrm{A}$ and $\mathrm{B}$ by acacetin and its 7-O-(6-O-malonylglucoside) derivative from Agastache rugosa. Int. J. Biol. Macromol. 2017, 104, 547-553. [CrossRef]

54. Brus, B.; Košak, U.; Turk, S.; Pišlar, A.; Coquelle, N.; Kos, J.; Stojan, J.; Colletier, J.P.; Gobec, S. Discovery, biological evaluation, and crystal structure of a novel nanomolar selective butyrylcholinesterase inhibitor. J. Med. Chem. 2014, 57, 8167-8179. [CrossRef]

55. Radic, Z.; Pickering, N.A.; Vellom, D.C.; Camp, S.; Taylor, P. Three distinct domains in the cholinesterase molecule confer selectivity for acetyl- and butyrylcholinesterase inhibitors. Biochemistry 1993, 32, 12074-12084. [CrossRef] [PubMed]

56. Jannat, S.; Balupuri, A.; Ali, M.Y.; Hong, S.S.; Choi, C.W.; Choi, Y.H.; Ku, J.M.; Kim, W.J.; Leem, J.Y.; Kim, J.E.; et al. Inhibition of $\beta$-site amyloid precursor protein cleaving enzyme 1 and cholinesterases by pterosins via a specific structure-activity relationship with a strong BBB permeability. Exp. Mol. Med. 2019, 51, 12. [CrossRef]

57. Abu-Aisheh, M.N.; Al-Aboudi, A.; Mustafa, M.S.; El-Abadelah, M.M.; Ali, S.Y.; Ul-Haq, Z.; Mubarak, M.S. Coumarin derivatives as acetyl- and butyrylcholinesterase inhibitors: An in vitro, molecular docking, and molecular dynamics simulations study. Heliyon 2019, 5, e01552. [CrossRef]

58. Baek, S.C.; Park, M.H.; Ryu, H.W.; Lee, J.P.; Kang, M.G.; Park, D.; Park, C.M.; Oh, S.R.; Kim, H. Rhamnocitrin isolated from Prunus padus var. seoulensis: A potent and selective reversible inhibitor of human monoamine oxidase A. Bioorg. Chem. 2019, 83, 317-325. [CrossRef]

59. Baek, S.C.; Lee, H.W.; Ryu, H.W.; Kang, M.G.; Park, D.; Kim, S.H.; Cho, M.L.; Oh, S.R.; Kim, H. Selective inhibition of monoamine oxidase A by hispidol. Bioorg. Med. Chem. Lett. 2018, 28, 584-588. [CrossRef]

60. Lee, H.W.; Ryu, H.W.; Kang, M.G.; Park, D.; Oh, S.R.; Kim, H. Potent selective monoamine oxidase B inhibition by maackiain, a pterocarpan from the roots of Sophora flavescens. Bioorg. Med. Chem. Lett. 2016, 26, 4714-4719. [CrossRef]

61. Baek, S.C.; Choi, B.; Nam, S.J.; Kim, H. Inhibition of monoamine oxidase A and B by demethoxycurcumin and bisdemethoxycurcumin. J. Appl. Biol. Chem. 2018, 61, 187-190. [CrossRef]

62. Ellman, G.L.; Courtney, K.D.; Andres, J.V.; Feather-Stone, R.M. A new and rapid colorimetric determination of acetylcholinesterase activity. Biochem. Pharmacol. 1961, 7, 88-95. [CrossRef]

63. Oh, J.M.; Kang, M.G.; Hong, A.; Park, J.E.; Kim, S.H.; Lee, J.P.; Baek, S.C.; Park, D.; Nam, S.J.; Cho, M.L.; et al. Potent and selective inhibition of human monoamine oxidase-B by 4-dimethylaminochalcone and selected chalcone derivatives. Int. J. Biol. Macromol. 2019, 137, 426-432. [CrossRef] [PubMed]

64. Trott, O.; Olson, A.J. AutoDock Vina: Improving the speed and accuracy of docking with a new scoring function, efficient optimization, and multithreading. J. Comput. Chem. 2010, 31, 455-461. [CrossRef] [PubMed] 
65. Pettersen, E.F.; Goddard, T.D.; Huang, C.C.; Couch, G.S.; Greenblatt, D.M.; Meng, E.C.; Ferrin, T.E. UCSF Chimera-A visualization system for exploratory research and analysis. J. Comput. Chem. 2004, 25, 1605-1612. [CrossRef] [PubMed]

66. Mills, J.E.; Dean, P.M. Three-dimensional hydrogen-bond geometry and probability information from a crystal survey. J. Comput. Aided Mol. Des. 1996, 10, 607-622. [CrossRef] [PubMed]

Sample Availability: Samples of the compounds are available from the authors.

(C) 2020 by the authors. Licensee MDPI, Basel, Switzerland. This article is an open access article distributed under the terms and conditions of the Creative Commons Attribution (CC BY) license (http://creativecommons.org/licenses/by/4.0/). 